\title{
Emission scan
}

National Cancer Institute

\section{Source}

National Cancer Institute. Emission scan. NCI Thesaurus. Code C94892.

The usual mode of scanner operation in which a tracer's distribution throug hout a subject is detected for subsequent processing into an image. 